\title{
Urothelial carcinoma with villoglandular differentiation: a study of 14 cases
}

\author{
Matthew Lim ${ }^{1}$, N Volkan Adsay ${ }^{1}$, David Grignon ${ }^{3}$ and Adeboye O Osunkoya ${ }^{1,2}$ \\ ${ }^{1}$ Department of Pathology, Emory University School of Medicine, Atlanta, GA, USA; ${ }^{2}$ Department of Urology, \\ Emory University School of Medicine, Atlanta, GA, USA and ${ }^{3}$ Department of Pathology, Indiana University \\ School of Medicine, Indianapolis, IN, USA
}

\begin{abstract}
Tumors of the urinary bladder may have a variety of histological patterns. Tumors with either glandular or villous features, such as villous adenomas, in situ adenocarcinomas, invasive adenocarcinomas, and variants of urothelial carcinoma such as micropapillary carcinomas have been described. However, urothelial carcinomas with both villous and glandular features have not been well characterized. We identified 14 cases of urothelial carcinoma with villoglandular differentiation. These cases were defined as having villoglandular features if they contained superficial finger-like processes lined by epithelium having true glandular lumina. Mean patient age at presentation was 70 years (range: $46-84$ years) with a male predominance (5:1). A total of 3 cases $(21 \%)$ were non-invasive, five cases $(36 \%)$ had lamina propria invasion, five cases $(36 \%)$ had muscularis propria invasion and one case $(\mathbf{7} \%)$ had extravesicular extension. A concurrent high-grade papillary urothelial carcinoma component was identified in 11 cases (79\%), micropapillary component in $5(36 \%)$ cases, in-situ urothelial carcinoma component in 3 cases $(21 \%)$, plasmacytoid component in 3 cases $(21 \%)$, invasive adenocarcinoma in 2 cases, sarcomatoid carcinoma component in one case (14\%), and small-cell carcinoma component in 1 case $(7 \%)$. Cystitis cystica et glandularis was present in 3 cases (21\%). Angiolymphatic invasion was identified in 3 cases $(21 \%)$. Histologically, the villoglandular components were composed of finger-like processes lined by glands intimately admixed with high-grade urothelial carcinoma. Many of the glands had cribriform features lined by non-mucin producing cuboidal to columnar cells. Urothelial carcinoma with villoglandular differentiation are high-grade tumors typically seen in elderly males, characterized by superficial filliform processes lined by glands intimately admixed with high-grade urothelial carcinoma (in situ or invasive) and other aggressive variants of urothelial carcinoma. These relatively rare tumors should be recognized as a variant of urothelial carcinoma.
\end{abstract}

Modern Pathology (2009) 22, 1280-1286; doi:10.1038/modpathol.2009.97; published online 10 July 2009

Keywords: invasive urothelial carcinoma; villoglandular differentiation

Tumors of the urinary bladder and other aspects of the urinary tract, particularly those with high cytological grade, may have a variety of histological patterns, including sarcomatoid, microcystic, nested, lymphoepithelioma-like, micropapillary, and small-cell patterns. Malignant and benign bladder tumors may have glandular or villous differentiation and these lesions include villous adenomas, in situ adenocarcinomas, invasive adenocarcinomas, and variants of urothelial carcinomas having glandular differentiation. Those lesions,

Correspondence: Dr AO Osunkoya, MD, Department of Pathology, Emory University School of Medicine, 1364 Clifton Road, NE, Room H174, Atlanta, Georgia 30322, USA.

E-mail: adeboye.osunkoya@emoryhealthcare.org

Received 24 February 2009; revised and accepted 26 May 2009; published online 10 July 2009 containing either glandular or villous features have been well described; however, little attention has been paid in the literature to urothelial neoplasms containing both of these features. In this series, we review the histological features of 14 cases of urothelial carcinoma with villoglandular differentiation and discuss clinicopathological features with emphasis on differentiation from other well-known malignant entities in the bladder.

\section{Materials and methods}

We identified 14 cases of urothelial carcinomas having villoglandular features between 1986 and 2008. A total of 13 cases were biopsy specimens, 2 of which had subsequent cystectomy specimens, and 1 case was from a urethral excision. These cases were 
defined as having villoglandular features if they contained superficial finger-like processes lined by epithelium having true glandular lumina intimately admixed with invasive or in situ urothelial carcinoma. Each of the cases were evaluated for the following features: presence of non-invasive and invasive urothelial carcinoma, depth of invasion, variants of urothelial carcinoma, adenocarcinoma component, cystitis cystica et glandularis, and angiolymphatic invasion. In all cases, spread from a colorectal primary was clinically excluded. This study was completed following the guidelines of and with approval from the Emory University Institutional Review Board.

\section{Results}

The clinical and pathological findings of the 14 cases of urothelial carcinomas with villoglandular differentiation are listed in Table 1. The mean patient age was 70 years (range: $46-84$ years) with a male predominance (male to female ratio of 5:1). A total of 3 cases $(21 \%)$ were non-invasive, 5 cases $(36 \%)$ had lamina propria invasion, 5 cases $(36 \%)$ had muscularis propria invasion, and 1 case $(7 \%)$ had extravesicular extension. Angiolymphatic invasion was identified in 3 cases $(21 \%)$. Cases with angiolymphatic invasion had micropapillary, small-cell carcinoma, or adenocarcinoma components in addition to urothelial carcinoma with villoglandular differentiation (Table 2).

Histologically, all the cases were composed of superficial finger-like processes lined by epithelium having true glandular lumina (Figures 1a-c). In the cases having a high-grade papillary urothelial carcinoma component, the finger-like processes were lined by glands intimately admixed with high-grade urothelial carcinoma. Many of the glands had cribriform features and were lined by non-mucin producing cuboidal to columnar cells (Figures 2a-4b). However, the size and shape of the glands were variable, with some being small and slit-like and others being large and adenoma-like.

Table 1 Clinicopathological findings in 14 cases of urothelial carcinoma with villoglandular differentiation

\begin{tabular}{lllll}
\hline Case number & Age/sex & Depth of invasion & Angiolymphatic invasion & Pathology \\
\hline 1 & 58/F & Non-invasive & Absent & HGU, ADENO \\
2 & 80/M & Lamina propria & Absent & HGU \\
3 & $79 / \mathrm{F}$ & Lamina propria & Absent & HGU, MP \\
4 & $61 / \mathrm{M}$ & Non-invasive & Absent & CCCG, HGU \\
5 & $62 / \mathrm{F}$ & Perivesical adipose tissue & Present & HGU, MP, SMCC \\
6 & $84 / \mathrm{M}$ & Lamina propria & Absent & HGU, CIS \\
7 & $78 / \mathrm{M}$ & Muscularis propria & Present & HGU, PUC \\
8 & $66 / \mathrm{M}$ & Lamina propria & Absent & CCCG, HGU, MP \\
9 & $63 / \mathrm{M}$ & Lamina propria & Absent & HGU, CIS, MP, SUC, PUC \\
10 & $83 / \mathrm{M}$ & Muscularis propria & Absent & PUC, CIS \\
11 & 80/M & Muscularis propria & Absent & ADENO \\
12 & $79 / \mathrm{M}$ & Non-invasive & ADENO \\
13 & $70 / \mathrm{M}$ & Muscularis propria & Pbsent & CCCG, HGU, MP, ADENO
\end{tabular}

Abbreviations: CCCG, cystitis cystica et glandularis; HGU, high-grade papillary urothelial carcinoma; CIS, urothelial carcinoma in situ; ADENO, adenocarcinoma; MP, micropapillary urothelial carcinoma (superficial); SUC, sarcomatoid urothelial carcinoma; SMCC, small cell carcinoma; PUC, plasmacytoid urothelial carcinoma.

Table 2 Histological findings in various cases of urothelial carcinoma with villoglandular differentiation

\begin{tabular}{|c|c|c|c|}
\hline Case number & Glandular morphology & Epithelial cell type & Lumen \\
\hline 1 & Cribriform and large irregular glands & Urothelial, columnar & Mucin, neutrophils \\
\hline 2 & Cribriform & Urothelial, cuboidal, columnar & Eosinophilic secretions \\
\hline 3 & Slit-like and irregular glands & Urothelial, cuboidal & Eosinophilic secretions, apoptotic bodies \\
\hline 4 & Cribriform and large irregular glands & Urothelial, columnar & Eosinophilic secretions, apoptotic bodies \\
\hline 5 & Small and irregular & Urothelial, cuboidal & Eosinophilic secretions \\
\hline 6 & Cribriform & Urothelial, cuboidal, columnar & Eosinophilic secretions \\
\hline 7 & Cribriform & Urothelial, columnar & Eosinophilic secretions \\
\hline 8 & Cribriform and large irregular glands & Urothelial, cuboidal & Eosinophilic secretions, apoptotic bodies \\
\hline 9 & Large irregular complex glands & Urothelial, columnar & Eosinophilic secretions, apoptotic bodies \\
\hline 10 & Cribriform and large irregular glands & Urothelial, columnar & Eosinophilic secretions \\
\hline 11 & Large irregular glands & Urothelial, columnar & Eosinophilic secretions \\
\hline 12 & Cribriform & Urothelial, columnar & Eosinophilic secretions \\
\hline 13 & Cribriform & Urothelial, columnar & Mucin \\
\hline 14 & Cribriform and large irregular glands & Urothelial, columnar & Eosinophilic secretions, apoptotic bodies \\
\hline
\end{tabular}



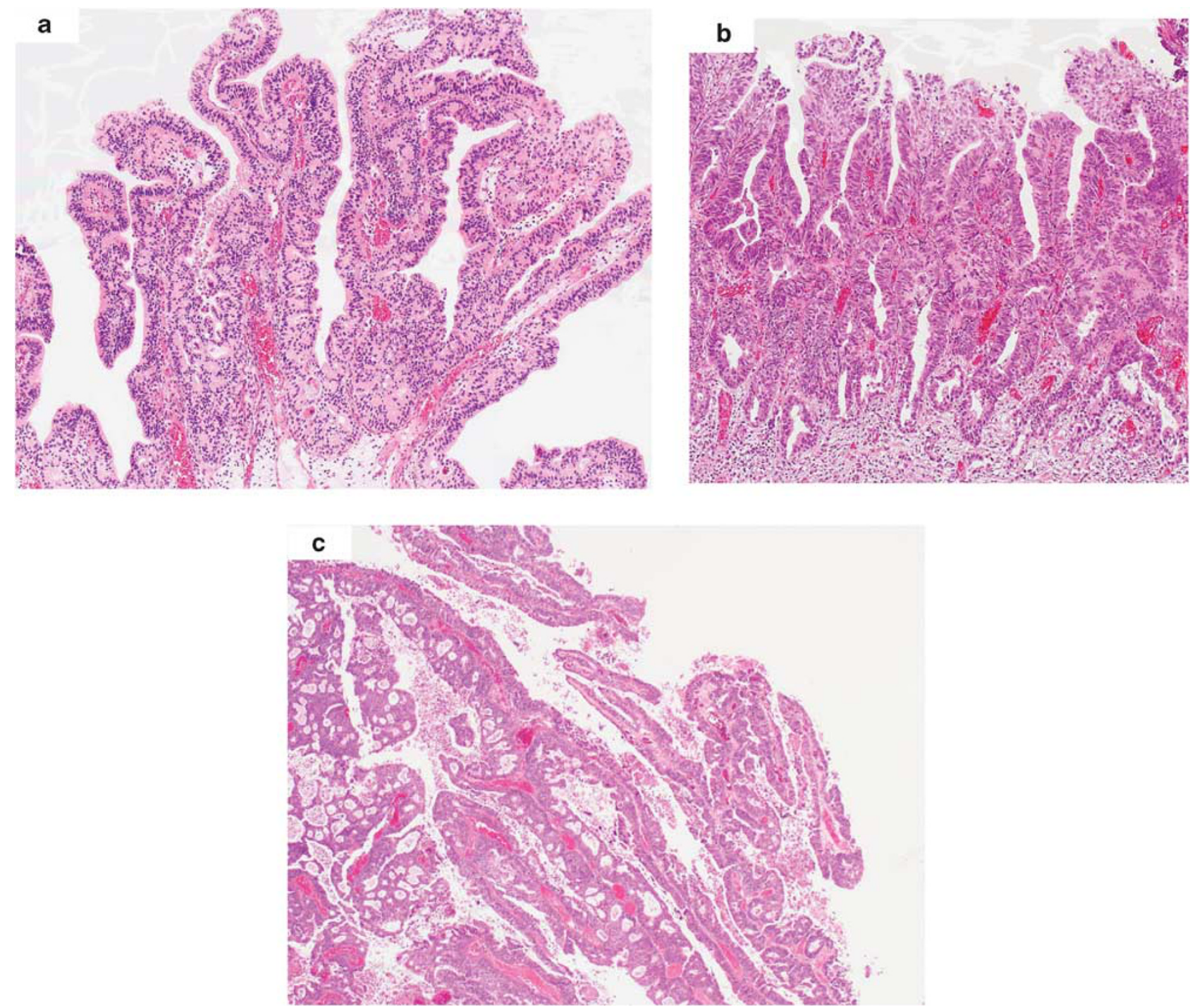

Figure 1 (a) Urothelial carcinoma with villoglandular differentiation with prominent villiform structures. (b) Urothelial carcinoma with villoglandular differentiation with prominent villiform structures showing marked nuclear pleomorphism. (c) Urothelial carcinoma with villoglandular differentiation with prominent villiform and acinar structures.

Luminal mucin was present in one of these cases. Variable quantities of intraluminal necrosis, apoptotic bodies, and eosinophilic secretions were present. The two cases of adenocarcinoma were composed of finger-like processes lined by glands composed of columnar cells, with one case containing luminal mucin (Figures $5 \mathrm{a}-\mathrm{b}$ ).

Multiple different urothelial carcinoma variants were identified in our cases. A concurrent highgrade papillary urothelial carcinoma component was identified in 11 cases (79\%), superficial micropapillary component in 5 cases (36\%) (Figures 6a-b), in-situ urothelial carcinoma component in 3 cases $(21 \%)$, plasmacytoid component in 3 cases $(21 \%)$ (Figure 7), invasive adenocarcinoma component in 2 cases $(14 \%)$, and small-cell carcinoma component in 1 case $(7 \%)$ (Figure 8). Individual cases rarely showed a single component; rather, various combinations of the abovementioned components were more often seen. Cystitis cystica et glandularis was present in 3 cases $(21 \%)$, only one of which had an adenocarcinoma component.

\section{Discussion}

Adult urothelium has the capacity to undergo several pathways of phenotypic cellular and structural differentiation as a result of the embryological origin of the bladder from the multipotent tissues of the cloacal endoderm and the mesodermal Wolffian ducts. ${ }^{1}$ Studies have shown that urothelium has the ability to undergo metaplastic change and is supported by cell culture experiments, which showed that glandular, transitional, and squamous differentiation may develop from a common neoplastic urothelial stem cell. ${ }^{2}$ 

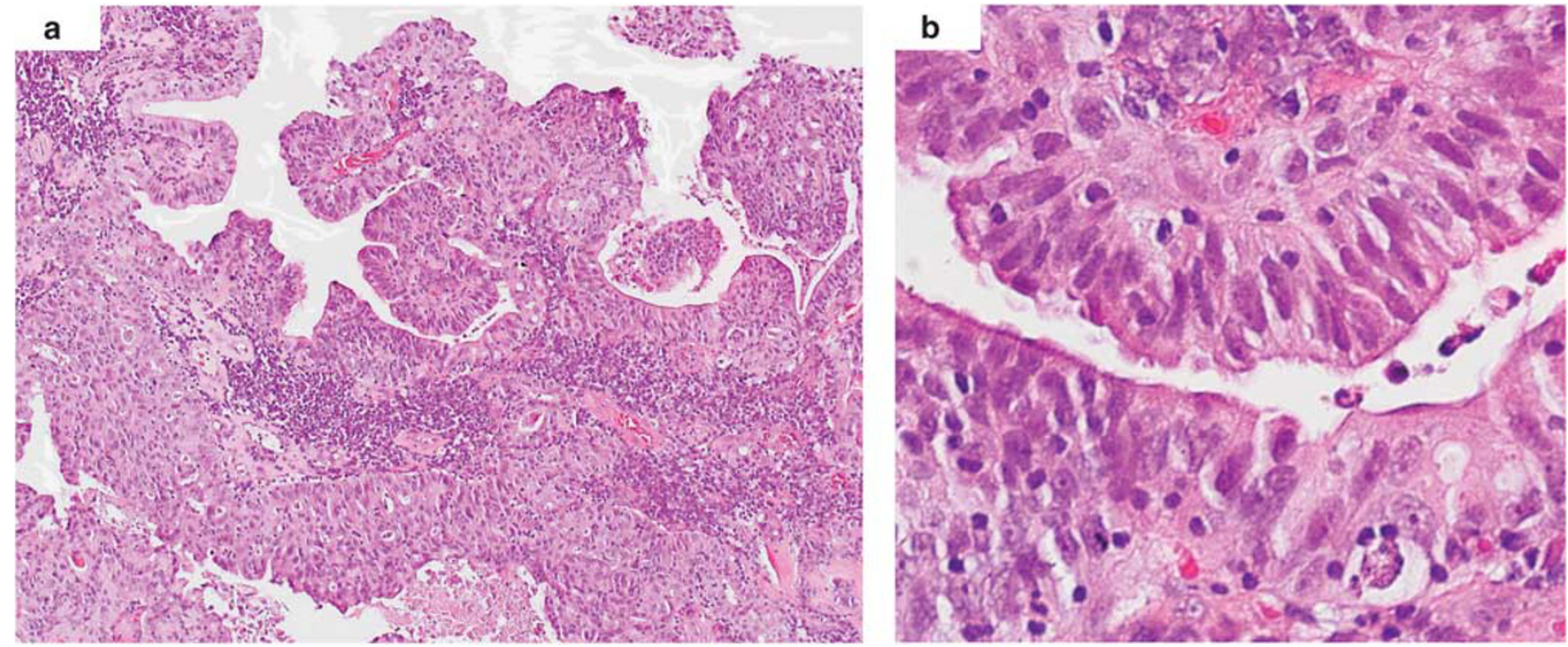

Figure 2 (a) Urothelial carcinoma with villoglandular differentiation with focal necrosis (bottom). (b) Pseudostratified glands with prominent cilia.

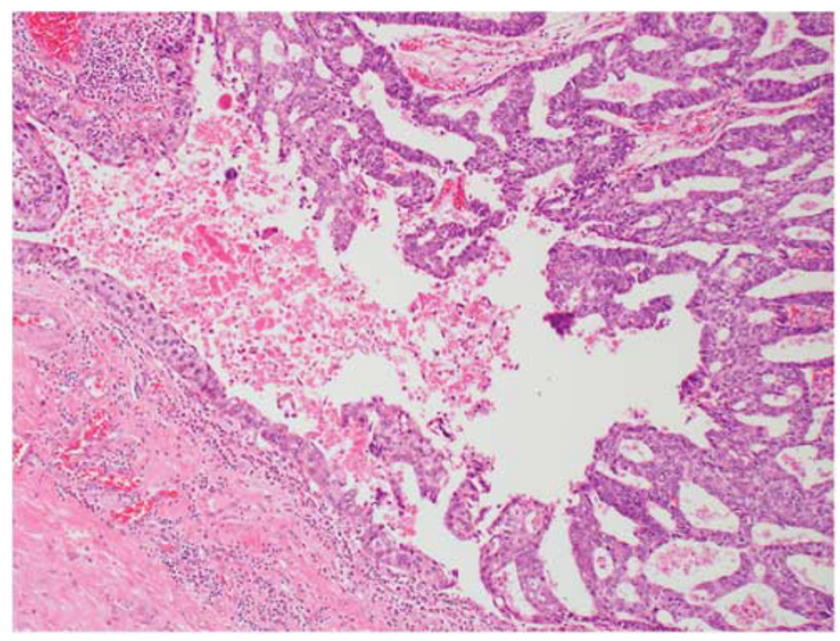

Figure 3 Urothelial carcinoma with villoglandular differentiation with necrosis and adjacent urothelial carcinoma in situ.

Urothelial carcinomas with villoglandular differentiation has features that overlap with other tumors of the urinary bladder including in situ adenocarcinomas, villous adenomas, micropapillary variant of urothelial carcinoma, and urothelial carcinomas with glandular differentiation. The presence of villous/papillary or glandular features in all of these lesions makes the diagnosis of urothelial carcinoma with villoglandular differentiation a challenging one. However, urothelial carcinoma with villoglandular differentiation has distinct characteristics, which differentiate it from the abovementioned lesions.

In situ adenocarcinomas are glandular lesions of the bladder that may have a mixture of three architectural patterns including papillary, cribriform, and flat patterns. ${ }^{3,4}$ Mixtures of papillary and cribriform patterns are most commonly seen and the presence of these two patterns may mimic urothelial carcinoma with villoglandular differentiation. Although in situ adenocarcinomas may show a papillary architecture, it does not form filliform finger-like projections, which are seen in villous adenomas and in urothelial carcinoma with villoglandular differentiation. ${ }^{3}$ The cribriform structures of in situ adenocarcinoma are not intimately admixed with or arise within a urothelial carcinoma, whereas the cribriform structures seen in our cases were admixed with high-grade urothelial carcinoma. ${ }^{3}$ The cribriform glands of in situ adenocarcinoma are lined by columnar epithelium with apical cytoplasm. ${ }^{3}$ In urothelial carcinoma with villoglandular differentiation, the cribriform glands were lined by non-mucin producing cuboidal to columnar cells.

Another tumor of the bladder that may seem similar to urothelial carcinoma with villoglandular differentiation, especially at low magnification, are villous adenomas. These lesions have finger-like processes, which are lined by pseudostratified epithelium and are morphologically indistinguishable from the villous and tubullovillous adenomas of the colon. ${ }^{5-9}$ Seibel et al, ${ }^{8}$ in their series on villous adenomas of the urinary tract, reported a case of villous adenoma with in situ adenocarcinoma, which showed an almost imperceptible transition to focal non-invasive papillary urothelial carcinoma. A case like this with a subtle transition between adenomatous and papillary urothelial elements may resemble a urothelial carcinoma with villoglandular differentiation. Although both have finger-like processes composed of glandular elements adjacent to urothelial carcinoma, the epithelial lining of urothelial carcinoma with villoglandular differentiation is not composed of columnar cells displaying nuclear stratification, nuclear crowding, or nuclear 

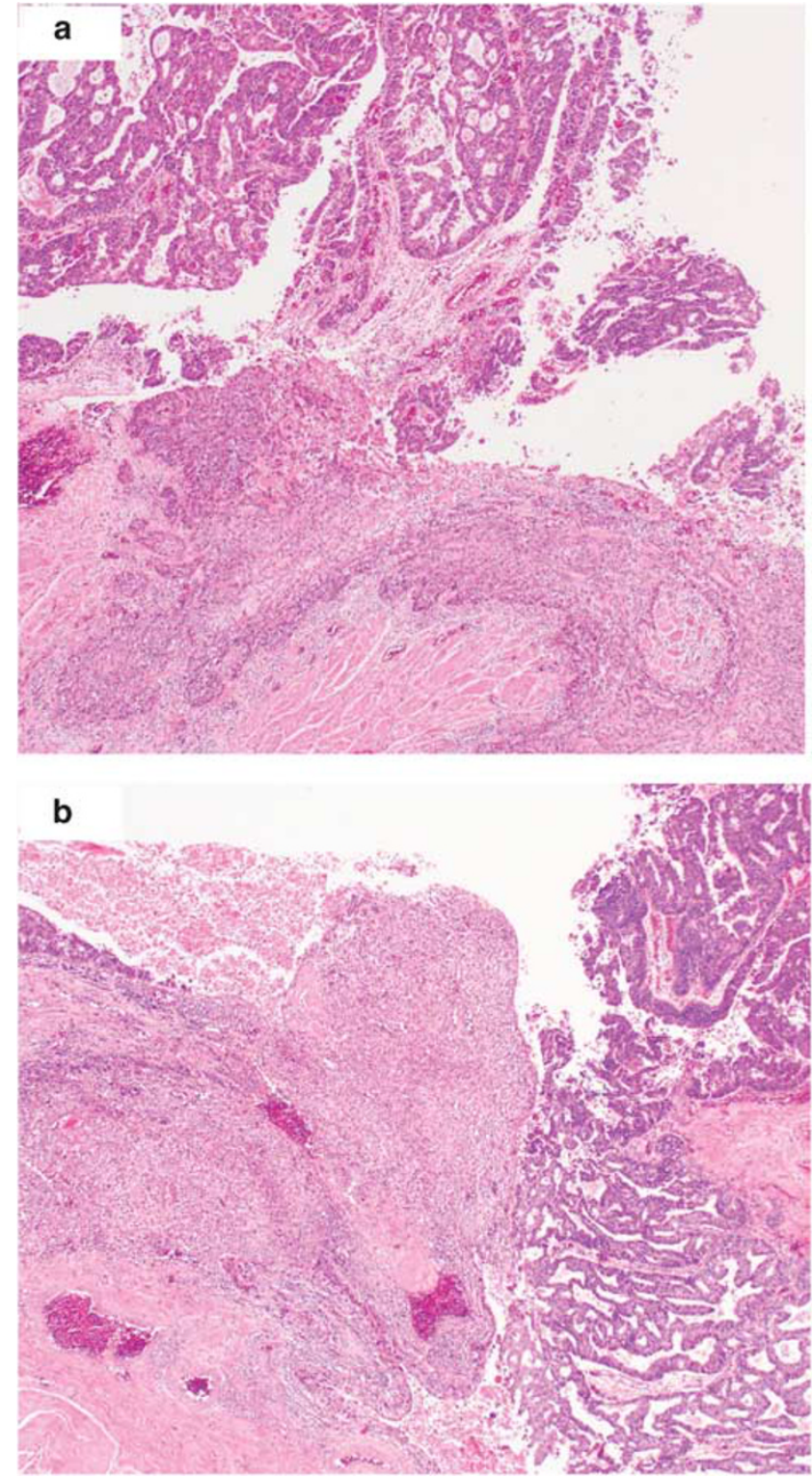

Figure 4 (a) Urothelial carcinoma with villoglandular differentiation with adjacent high-grade urothelial carcinoma invasive into muscularis propria. (b) Urothelial carcinoma with villoglandular differentiation with adjacent high-grade urothelial carcinoma invasive into muscularis propria.

hyperchromasia. Instead, the lining cells of urothelial carcinoma with villoglandular differentiation are composed of cuboidal to columnar cells organized in a cribriform architecture. Intraluminal necrosis, apoptotic bodies, and eosinophilic secretions may be present in the lumens of urothelial carcinoma with villoglandular differentiation.

The in situ component of micropapillary variant of urothelial carcinoma may also mimic urothelial carcinoma with villoglandular differentiation. The micropapillary pattern is defined by slender delicate filliform processes, often with a fibrovascular core. Cytologically, the micropapillary component has a high-grade nuclear morphology with high nuclear-

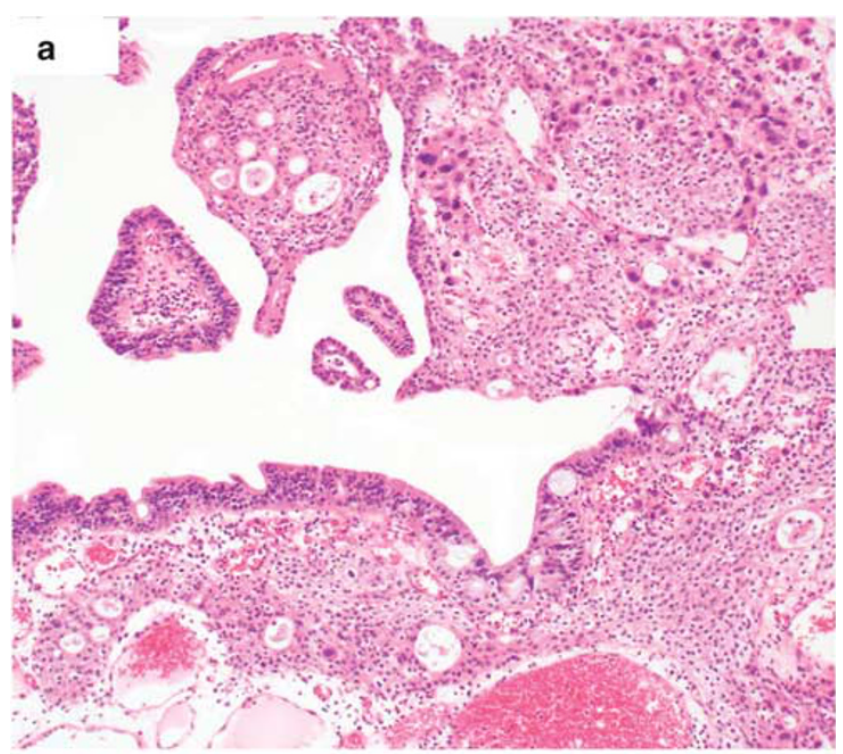

b

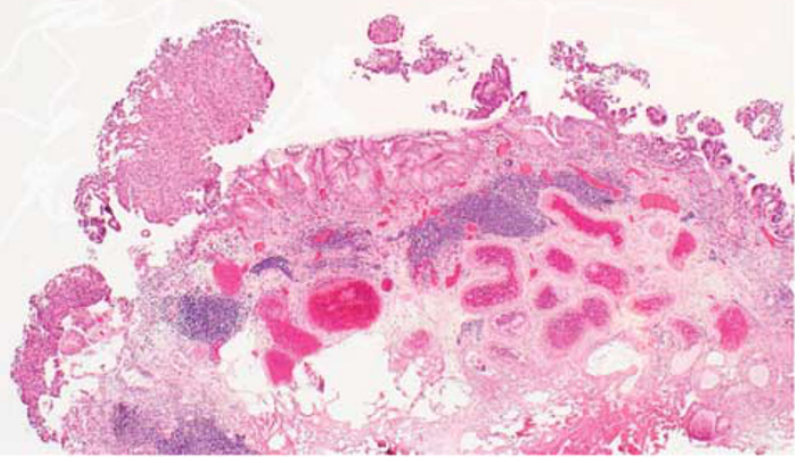

Figure 5 (a) Urothelial carcinoma with villoglandular differentiation with lamina propria invasion and adjacent adenocarcinoma in situ. (b) Urothelial carcinoma with villoglandular differentiation with adjacent adenocarcinoma in situ.

to-cytoplasmic ratio and abundant eosinophilic or slightly clear cytoplasm. ${ }^{10}$ Urothelial carcinoma with villoglandular differentiation, in contrast, is characterized by prominent filliform structures lined by glands having a cribriform architecture. Both share a high-grade nuclear morphology and cells have cuboidal appearance.

High-grade urothelial carcinomas may include foci of glandular differentiation. ${ }^{11-14}$ These urothelial carcinomas having unequivocal glandular differentiation have been designated as having a 'mixed' or 'glandular' differentiation. This designation is not used for typical urothelial carcinomas containing pseudoglandular structures or occasional mucin-containing cell, as cytoplasmic mucin-containing cells are present in $\sim 14 \%$ of urothelial carcinomas. $^{1,15}$ Glandular differentiation, which may contain tubular or enteric glands with mucin secretion, is present in about $6 \%$ of urothelial 


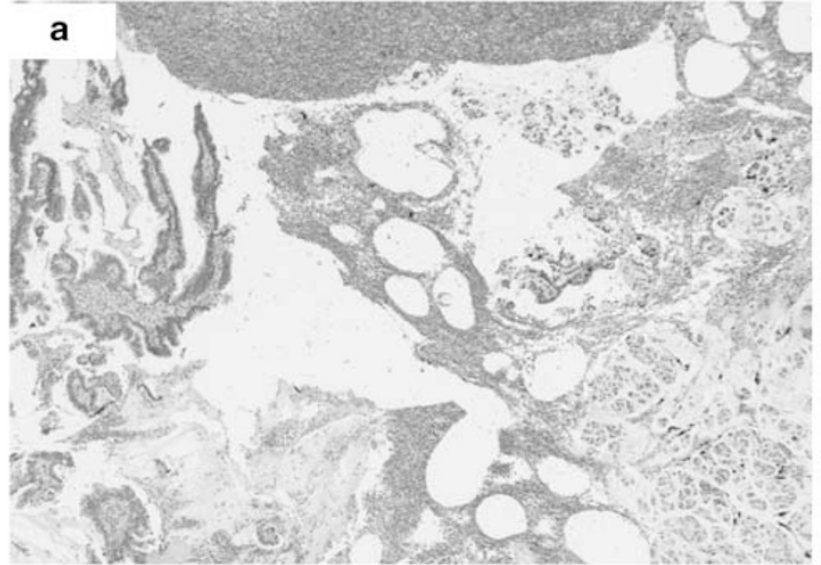

b

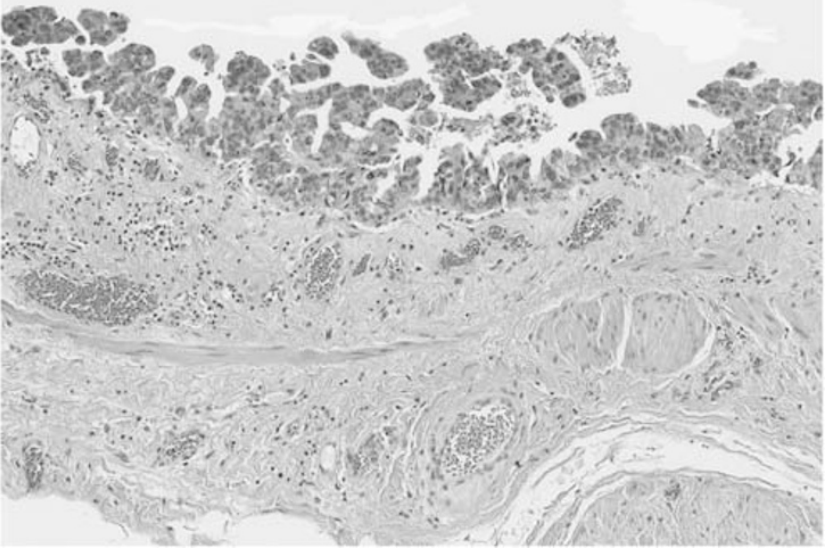

Figure 6 (a) Urothelial carcinoma with villoglandular differentiation (left) with adjacent micropapillary urothelial carcinoma (right). (b) Separate focus of non-invasive micropapillary urothelial carcinoma.

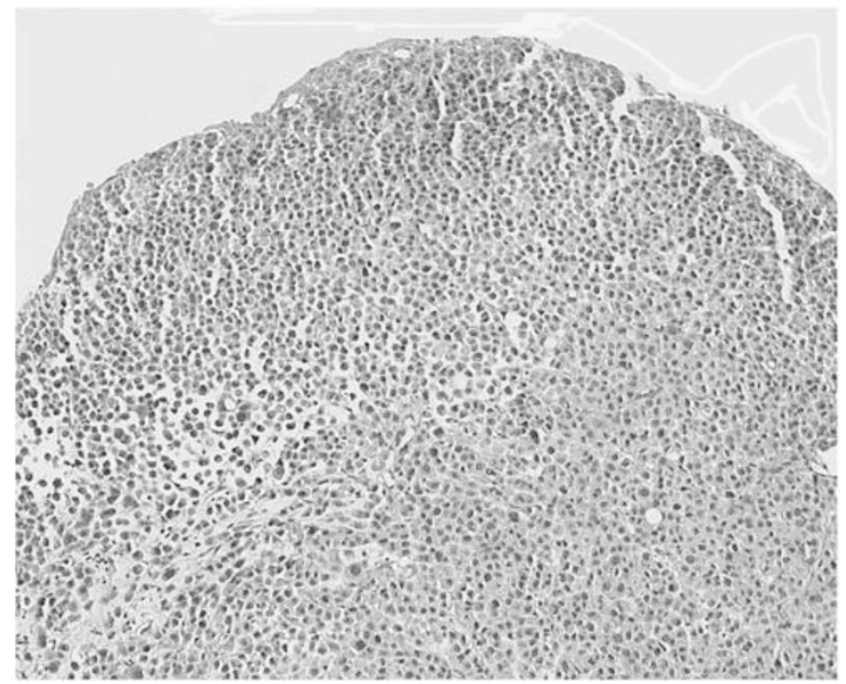

Figure 7 Separate focus of plasmacytoid urothelial carcinoma.

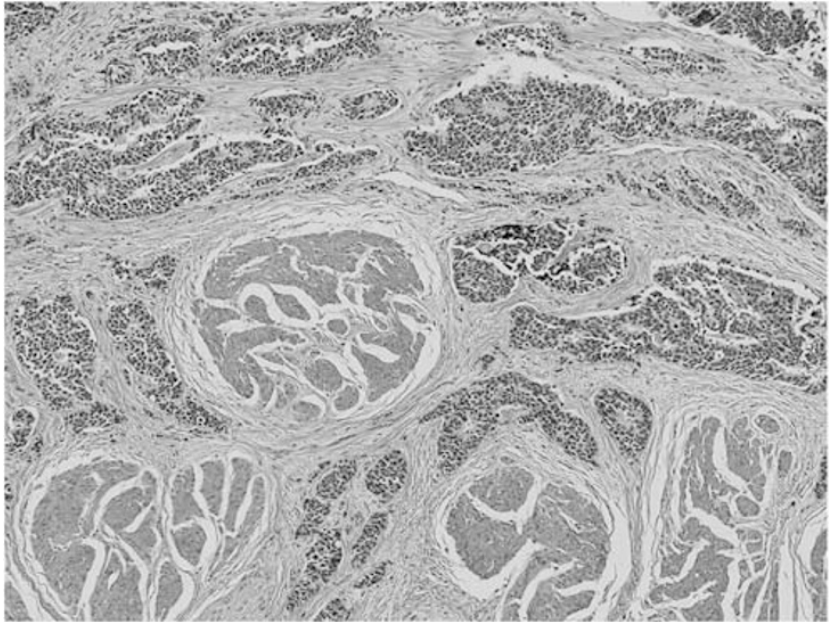

Figure 8 Separate focus of small-cell carcinoma invasive into muscularis propria.

carcinomas of the bladder. ${ }^{12}$ Differentiating urothelial carcinoma with villoglandular differentiation from urothelial carcinoma with glandular differentiation may be challenging, with the only differentiating characteristic being the presence of prominent villiform structures in urothelial carcinoma with villoglandular differentiation.

The distinction between urothelial carcinoma with villoglandular differentiation and direct extension or metastasis from a colorectal primary may be challenging, especially on small biopsies. This is especially noteworthy because we know from experience that colorectal adenocarcinoma involving the bladder may actually colonize the urothelium and mimic in situ disease. It is thus critical as was done in our series to clinically exclude the presence of a colorectal mass in these patients. Involvement of the bladder by prostatic duct adenocarcinoma is another important differential, which can easily be excluded by negative immunohistochemical stains for prostate-specific antigen.

High-grade urothelial carcinomas may have mixtures of urothelial cell carcinoma variants and adenocarcinomas. In a series studying 448 transurethral resection of bladder tumor specimens, $11 \%$ of cases of high-grade urothelial carcinomas had multiple types of mixed histological components including squamous, glandular, sarcomatoid, micropapillary, small cell, and plasmacytoid variants. ${ }^{16}$ Chan et $a l^{3}$ reported that of 19 in situ adenocarcinomas cases, follow-up of concurrent and subsequent specimens showed five patients having small-cell carcinoma and nine having urothelial carcinoma, of which four were micropapillary variants. In our study, the most common component found in association with urothelial carcinoma with villoglandular differentiation was superficial micropapillary $(36 \%)$ followed by plasmacytoid variants $(21 \%)$. One case was involved by small-cell carcinoma. These variant histologies portend a worse 
prognosis and the presence of urothelial carcinoma with villoglandular differentiation should increase the suspicion for other variant patterns, particularly superficial micropapillary variants of urothelial carcinoma. ${ }^{10,17-21}$

In summary, the presence of variant histologies in a significant percentage of urothelial carcinoma with villoglandular differentiation cases suggests that, compared with typical urothelial cell carcinomas, these tumors are more likely to have a poorer prognosis. A total of $5(36 \%)$ of our cases had lamina propria invasion, $5(36 \%)$ cases had muscularis propria invasion, and $1(7 \%)$ case had extravesicular extension. A total of 3 cases (21\%) had angiolymphatic invasion. This data also suggest that urothelial carcinoma with villoglandular differentiation behaves aggressively. However, owing to our limited follow-up and patient population, additional studies are needed to determine the true prognostic significance of this variant.

\section{Disclosure/conflict of interest}

The authors declare no conflict of interest.

\section{References}

1 Kunze E, Francksen B, Schulz H. Expression of MUC5AC apomucin in transitional cell carcinomas of the urinary bladder and its possible role in the development of mucus-secreting adenocarcinomas. Virchows Arch 2001;439:609-615.

2 Offner FA, Ott G, Povey S, et al. Characterization of the new bladder cancer cell line HOK-1: expression of transitional, squamous and glandular differentiation patterns. Int J Cancer 1991;49:122-128.

3 Chan TY, Epstein JI. In situ adenocarcinoma of the bladder. Am J Surg Pathol 2001;25:892-899.

4 O'Brien AM, Urbanski SJ. Papillary adenocarcinoma in situ of bladder. J Urol 1985;134:544-546.

5 Adegboyega PA, Adesokan A. Tubulovillous adenoma of the urinary bladder. Mod Pathol 1999;12:735-738.

6 Channer JL, Williams JL, Henry L. Villous adenoma of the bladder. J Clin Pathol 1993;46:450-452.

7 Cheng L, Montironi R, Bostwick DG. Villous adenoma of the urinary tract: a report of 23 cases, including 8 with coexistent adenocarcinoma. Am J Surg Pathol 1999;23:764-771.

8 Seibel JL, Prasad S, Weiss RE, et al. Villous adenoma of the urinary tract: a lesion frequently associated with malignancy. Hum Pathol 2002;33:236-241.

9 Trotter SE, Philp B, Luck R, et al. Villous adenoma of the bladder. Histopathology 1994;24:491-493.

10 Amin MB, Ro JY, el-Sharkawy T, et al. Micropapillary variant of transitional cell carcinoma of the urinary bladder. Histologic pattern resembling ovarian papillary serous carcinoma. Am J Surg Pathol 1994;18: 1224-1232.

11 Grace DA, Winter CC. Mixed differentiation of primary carcinoma of the urinary bladder. Cancer 1968;21:1239-1243.

12 Lopez-Beltran A, Cheng L. Histologic variants of urothelial carcinoma: differential diagnosis and clinical implications. Hum Pathol 2006;37:1371-1388.

13 Murphy WM, Grignon D, Perlman EJ. Tumors of the Kidney, Bladder and Related Urinary Structures. Armed Forces Institute of Pathology: Washington DC, 20.

14 Young RH, Eble JN. Unusual forms of carcinoma of the urinary bladder. Hum Pathol 1991;22:948-965.

15 Kunze E, Francksen B. Histogenesis of nonurothelial carcinomas of the urinary bladder from pre-existent transitional cell carcinomas. A histopathological and immunohistochemical study. Urol Res 2002;30:66-78.

16 Wasco MJ, Daignault S, Zhang Y, et al. Urothelial carcinoma with divergent histologic differentiation (mixed histologic features) predicts the presence of locally advanced bladder cancer when detected at transurethral resection. Urology 2007;70:69-74.

17 Black PC, Brown GA, Dinney CP. The impact of variant histology on the outcome of bladder cancer treated with curative intent. Urol Oncol 2009;27:3-7.

18 Johansson SL, Borghede G, Holmang S. Micropapillary bladder carcinoma: a clinicopathological study of 20 cases. J Urol 1999;161:1798-1802.

19 Nigwekar P, Tamboli P, Amin MB, et al. Plasmacytoid urothelial carcinoma: detailed analysis of morphology with clinicopathologic correlation in 17 cases. Am J Surg Pathol 2009;33:417-424.

20 Pan CX, Yang XJ, Lopez-Beltran A, et al. c-Kit expression in small cell carcinoma of the urinary bladder: prognostic and therapeutic implications. Mod Pathol 2005;18:320-323.

21 Samaratunga $\mathrm{H}$, Khoo K. Micropapillary variant of urothelial carcinoma of the urinary bladder; a clinicopathological and immunohistochemical study. Histopathology 2004;45:55-64. 